\title{
In Situ Atomic Force Microscopy (AFM) Study of Oxygen Reduction Reaction on a Gold Electrode Surface in a Dimethyl Sulfoxide (DMSO)-Based Electrolyte Solution
}

Can Liu, and Shen Ye

Institute for Catalysis, Hokkaido University, Sapporo 001-0021, Japan

${ }^{\mathrm{Z}}$ Corresponding author. Phone: +81-117069126; Email: ye@cat.hokudai.ac.jp. 


\section{Experimental methods}

1) The preparation of Au thin film for EC-AFM study

The $\mathrm{Au}$ film was deposited on a mica substrate by helicon sputtering. Prior to deposition, the chamber was evacuated to a base pressure of $10^{-4} \mathrm{~Pa}$. Then argon gas was purged into the chamber at a flow rate of $15 \mathrm{sccm}$ (standard-state cubic centimeter per minute), keeping a pressure of $0.135 \mathrm{~Pa}$ during deposition. A sputtering power of $30 \mathrm{~W}$ was used for the deposition at room temperature, which lasted for 14 min, producing a film of $80 \mathrm{~nm}$ thick with surface roughness of $0.7 \mathrm{~nm}$.

\section{2) AFM cell setup}

A three electrodes assembly was home-made for a commercially available AFM (Agilent 5500) with a tapping mode under electrochemical potential control. Figure S1 shows the schematic of the electrochemical cell. The Au film on a mica substrate was fixed between a Teflon plate and a supporting steel plate, exposing a circle area of $0.5 \mathrm{~cm}^{2}$ on the Au film as working electrode. The Teflon plate was made thin enough in order to enable the AFM scanner to approach the sample surface. The $\mathrm{Au}$ film was electronically connected to the steel plate by a thin aluminum foil, which is not exposed to the solution. A Teflon tape was placed between the steel plate and the AFM sample stage to insulate the electrode from sample stage. $\mathrm{Li}$ wires were employed as counter and reference electrodes. The solution of $0.1 \mathrm{M} \mathrm{\textrm {LiClO } _ { 4 }}$ dissolved in DMSO saturated with $\mathrm{O}_{2}$ was used as the electrolyte.

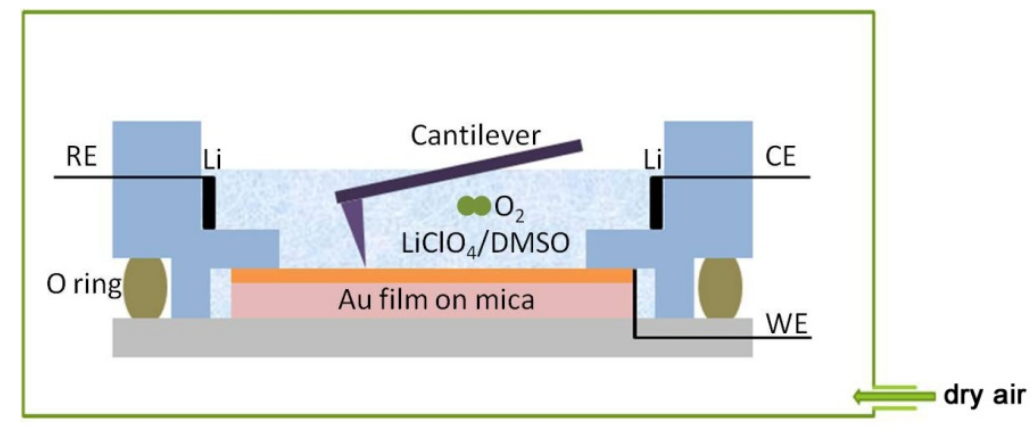

Figure S1. A schematic drawing of the $\mathrm{Li}-\mathrm{O}_{2}$ cell in the EC-AFM experiment.

3) Details of AFM image scanning

With the free amplitude set at $5.3 \mathrm{~V}$, the set-point, the integral gain and the proportional gain were optimized when the trace/retrace profiles just overlapped. Thus, a minimum scanning force could be used so as to avoid probe effect that may damage the weakly adhered surface species. 

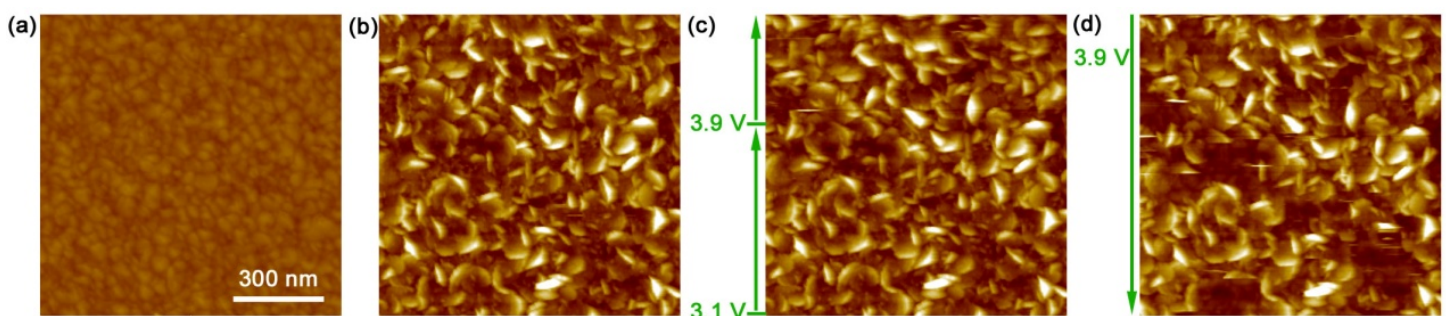

(e)
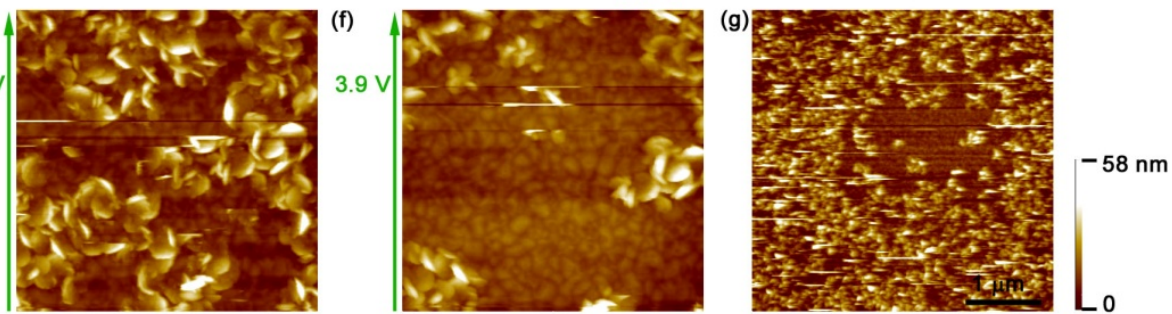

Figure S2. The probe effect for the in-situ imaging during OER. The AFM images of (a) the pristine Au electrode surface at initial OCP and (b) the surface after ORR, i.e. through potential sweep to $2.2 \mathrm{~V}$ at $5 \mathrm{mV} / \mathrm{s}$. (c-f) The in situ AFM images during OER, i.e. through potential sweep from OCP $3.1 \mathrm{~V}$ to $3.9 \mathrm{~V}$ at $5 \mathrm{mV} / \mathrm{s}$ and then holding at $3.9 \mathrm{~V}$ for a long time, all acquired at the same site of (b) within the area of $1^{*} 1 \mu \mathrm{m}^{2}$. The images of (c-e) are the first three images taken during OER, and (f) is the 7th image showing the removal of most ORR deposits. (g) The AFM image taken within a large area of $4 * 4 \mu \mathrm{m}^{2}$ at OCP after OER, showing that many particles still remained on the surface except for the small area that has been repeatedly scanned with probe.

Figure S3 shows potential of the gold electrode as a function of capacity during a galvanostatic polarization $\left(16 \mu \mathrm{A} / \mathrm{cm}^{2}\right)$.

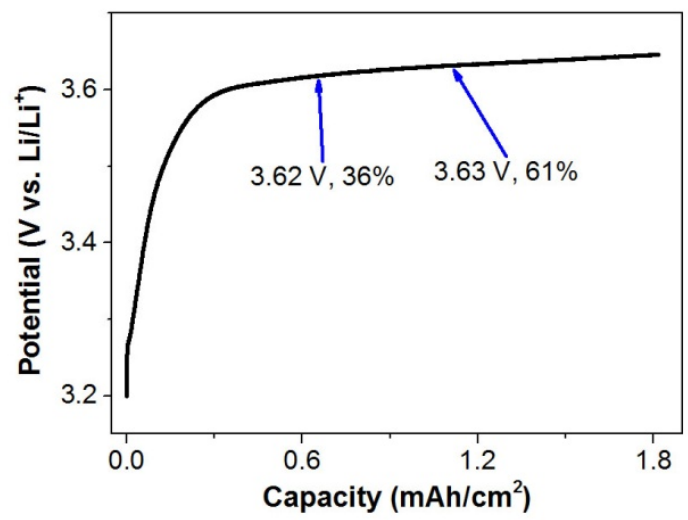

Figure S3. The galvanostatic OER curve at $16 \mu \mathrm{A} / \mathrm{cm}^{2}$ to the same capacity of ORR with $10 \mathrm{mM}$

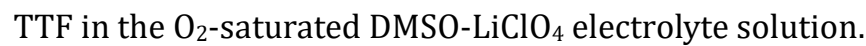

